\section{Statues: sculpting a tarnished legacy}

Nature's editors have often courted controversy by taking provocative stances. In some cases, such as the 1908 editorial supporting the admission of women to scientific societies (Nature 78, 226-228, 1908), this has reflected well on the journal's legacy. In others, such as the 1968 piece suggesting that the Cultural Revolution would benefit Chinese science (Nature 217, 1196-1197; 1968), it has not. I fear that your discussion of the statue of surgeon J. Marion Sims (1813-83) falls into the latter category (Nature 549, 5-6; 2017).

You should have consulted scientists of colour and historians of science before opining on the right way to remember such a fraught and painful history. In my view, your vague and euphemistic discussion of Sims' work 'whitewashes' (to use your term) his legacy more effectively than removing his statue ever could. Melinda Baldwin Washington DC, USA.

mbaldwin@aip.org

\section{Statues: researchers to mind their history}

Your Editorial created one more flashpoint in the current US debate about Confederate monuments (see Nature 549, 5-6; 2017 and Nature http://doi. org/ccvm; 2017).

The concern is what kind of history we memorialize in the statues of J. Marion Sims (1813-83) that stand outside the New York Academy of Medicine and in South Carolina and Alabama. As historians of science and medicine, we hope that the controversy over these will stop researchers relying on stories of scientific achievement that are blind to the moral and ethical assumptions and practices that made such achievements possible.

Sims used enslaved women to perfect a technique for repairing fistulas resulting from traumatic births. He was dubbed "the father of American gynaecology" by generations of white physicians (see also M. H. Green Nature 549, 160; 2017). Many contemporary writers question whether Sims' practices should be viewed as unethical, given that he worked in an era when the use of slave bodies for medical experimentation was common and sanctioned by the US medical profession. This assumes that there were no objections to Sims' experiments at the time, but some physicians in the north and south of the United States found them controversial and excessive (Anon. N. Am. Med. Chir. Rev. 2, 635-652; 1858).

You remark that Sims' achievements saved the lives of "black and white women alike". There is little evidence that he or other white physicians of his time applied these to improve treatment for black women. Well into the twentieth century, it was more common to deny black women any treatment at all for gynaecological ills.

Evelynn M. Hammonds Harvard University, Cambridge, Massachusetts, USA. Susan M. Reverby Wellesley College, Massachusetts, USA. evelynn_hammonds@harvard.edu

\section{Statues: an editorial response}

In the 7 September issue of Nature, we published an Editorial that provoked a widespread response (Nature 549, 5-6; 2017). We have since published representative criticisms, including those in this issue, as well as a related article by an expert (see page 309). After our intensive consideration of those responses, as well as internal and external discussions, I think it important to say the following.

The Editorial was wrong in warning that there could be risks associated with removing statues or altering the names of awards or streets that honour researchers who committed atrocious acts in the name of science. We did not adequately explore the ramifications of this statement or subject it to sufficient scrutiny. Many people, internally and externally, have pointed out that the statement is not true. Removing such statues or other memorials does not erase these individuals or their acts from history.

Beyond that fundamental error in the Editorial, the arguments throughout the piece - including an inappropriate framing of the example of J. Marion Sims and its overall tone were naive and unintentionally served to reinforce the insidious notion that women, people of colour and minority groups do not have a place in science. This notion is wrong.

We did not recognize how destructive the overall Editorial was and the effects that it could have.

As the editor ultimately accountable for Nature's content, I want to state that neither I nor any of my colleagues can defend the Editorial. It was the result of a process that on this occasion failed to rise to our standards of argument and editorial treatment. For this failure, I apologize.

The failure resulted from a combination of particular circumstances at the time and from systemic aspects of our workflows and sensitivities. For the latter, we recognize the immediate need to make extra effort to consult people of relevant expertise and lived experience. Although there was such external consultation with experts in the origination of this Editorial, we lost sight of that care in following it through. We failed to consult adequately the colleagues from many backgrounds who would have alerted us to the flaws and insensitivities in some of the language and arguments.

We commit to doing better from here on, and to working harder to be more inclusive in our processes. As part of this, we will appoint a group that will seek external advice to assess further what happened in this particular situation and to firmly guide us in adjusting our published content and internal practices.

We cannot wish away what we published, but we can make it clear to its readers that it was wrong. Accordingly, we will point readers to this editorial statement from the original Editorial and from related content.

Looking forward, we will also invite people to discuss broader issues in the sometimes troubled past and present of research, and to examine the impacts on diverse people within and outside the research community. We will do this in ways that will inform not only our content but also our editorial ability to be mindful.

Philip Campbell

Editor-in-Chief, Nature

\section{No chaos in the satellite-data record}

The use of the slang term snafu (indicating a confused or chaotic state) in your headline 'Satellite snafu masked true sea-level rise for decades' undermines the satellite record's crucial contribution to the precise measurement of indicators of Earth's changing climate (Nature 547, 265-266; 2017).

The correction you report represents less than 1 centimetre of the total sea-level increase of $8 \mathrm{~cm}$ or more that has been observed since 1993. Removing this small correction helped to reveal that the globally averaged rise in sea levels is accelerating. We used solid analysis and detective work to refine the accuracy of the satellite-data record to within less than $1 \mathrm{~cm}$ - not to fix a snafu.

R. Steven Nerem University of Colorado, Boulder, USA.

Anny Cazenave Laboratory of Geophysical and Oceanographic Studies (LEGOS), Toulouse, France. John Church University of New South Wales, Sydney, Australia. nerem@colorado.edu 